\title{
Risk Factors for Overweight and Obesity among Mexican Children in New York
}

\author{
Esperanza Tuñón-Pablos ${ }^{1}$ and Joanna Dreby ${ }^{2}$ \\ ${ }^{1}$ Department of Society and Culture, El Colegio de la Frontera Sur (ECOSUR), Carretera Panamericana y Periférico Sur $s / n$, \\ Barrio María Auxiliadora, 29290 San Cristóbal de Las Casas, CHIS, Mexico \\ ${ }^{2}$ Department of Sociology, University at Albany, SUNY, Arts \& Sciences 327, 1400 Washington Avenue, Albany, NY 12222, USA
}

Correspondence should be addressed to Joanna Dreby; jdreby@albany.edu

Received 11 September 2015; Accepted 4 January 2016

Academic Editor: Pranitha Maharaj

Copyright (C) 2016 E. Tuñón-Pablos and J. Dreby. This is an open access article distributed under the Creative Commons Attribution License, which permits unrestricted use, distribution, and reproduction in any medium, provided the original work is properly cited.

\begin{abstract}
This paper analyses the risk factors for being overweight or obese among the children of Mexican migrants in the United States. It draws on a qualitative study consisting of in-depth interviews and participant observation with 30 parents in New York State. Findings indicate risks related to nutritional deficiencies and food insecurity before migration, adaptation to US lifestyles, and the cultural tendency to value being overweight as a sign of greater health and higher socioeconomic status. Findings also show that mothers use various strategies to resist the excessive consumption of fast food, yet they simultaneously experience dilemmas around the family's consumption due to the gender norm that women are responsible for children's diet.
\end{abstract}

\section{Introduction}

Obesity is one of the principle risk factors of diabetes, which is one of the most significant health problems in the world today. According to the International Federation of Diabetes, 78 thousand children worldwide develop Type 1 diabetes every year. Along with the World Health Organization, they estimate that, at the current rate, by 2030 there will be 550 million diabetics globally. Experts agree that the best way forward is to focus not on treatment but rather on prevention, specifically on obesity prevention $[1,2]$.

Although it has been shown that genetics contribute to the obesity epidemic, it is impossible that in only 30 years genetic changes have been significant enough to fully explain the rate of growth in obesity levels worldwide. Clearly, the environment modifies the susceptibility of genes to different lifestyles [3]. Contributing to the worldwide intergenerational obesity epidemic are various other factors, those that are physiological, familial, social, economic, cultural, and political in origin $[4,5]$. These factors help to explain changes in diet over the past thirty years, specifically the decrease in fiber consumption and the increase in the consumption of fats and refined sugars.
Migrants are an especially at risk population [6, 7]. In middle income countries, like Mexico, rates of being overweight or obese are the highest in more developed regions and among the poor $[8,9]$; these groups may be especially prone to migration. In developed countries, like the United States, the prevalence is the greatest among low-income people as well as minority and migrant populations [10]. Among migrants, the high prevalence of being overweight or obese is best explained by sudden changes in diet, in both the preparation and consumption of food, changes that expose migrants to what some describe as an "accelerated nutritional transition" [11]. The children of migrants, born and raised in the United States, are an especially vulnerable population.

According to the Center of Disease Control [12], rates of diabetes in the United States are among the highest in the world, with $9.3 \%$ of the population in 2012 diagnosed with Type 1 or Type 2 diabetes. The highest rates are found among American Indians/Alaska Natives at $15.9 \%$ followed by nonHispanic blacks at 13.2\%, Hispanics (12.8\%), Asian Americans (9\%), and white non-Hispanics (7.6\%). Among Hispanics, rates are the highest among Puerto Ricans (14.8\%) followed by Mexican Americans at $13.9 \%$, higher than the national average. It is highly likely that this is an undercount given 
that undocumented Mexican migrants do not have access to health insurance and are more likely to go undiagnosed and not be counted in these statistics.

Moreover, Hispanics have the highest rates of childhood obesity in the United States [13]. D'Alonzo et al. [14] show that 17 percent of Latino girls and 27 percent of Latino boys are considered obese; they are 1.4 times more likely to become overweight or obese than white non-Hispanic children. In the absence of measures to reverse these trends, D'Alonzo et al. [14] estimate that, by $2030,90 \%$ of Mexican-origin people in the United States will become overweight or obese, as Latinos' risk of overweight and obesity increases exponentially by the number of years they have lived in the United States.

Despite the fact that African Americans currently have higher rates of obesity, Latinos' consumption habits are of growing concern. Demographic data predicts rapid growth of the Latino population in the United States; by 2060, one-third of US citizens will be of Hispanic origin, up from just a sixth of the population in 2012 [15]. There is no doubt that increases in Latino obesity rates over time will call for increases in public health expenditures for this growing social problem [16].

Existing research clearly indicates a growing social problem of becoming overweight or obese, yet we know little about the everyday practices among families that may contribute to these problems. To this end, this study qualitatively explores the various risk factors for becoming overweight or obese among a specific group of Latinos in the United States: Mexican migrant families. We focus on mothers' and fathers' accounts of their children's diets and their families' dietary decisions. Food insecurity before migration, adaptations to US lifestyles, and cultural preferences for being overweight as a symbol of good health and higher socioeconomic status may help to explain overweight and obesity rates among Latinos. Additionally, we identify the strategies mothers use to combat these risks - and the gender dilemmas they experience around the family's consumption habits-as possible opportunities for intervention.

Although this study is not representative of all Latino groups, Mexicans constitute the highest percentage of migrants and Latinos in the United States. In fact, Mexican Americans are the largest ethnic minority group in the United States and the third largest group in the state of New York; projections of the continued growth of this population are of great concern to the health sector. Better understanding of Mexican Americans' experiences in making decisions about their children's diets is significant for public health decisions affecting this population and can also shed light on the processes that may be experienced by other groups.

\section{Methodology}

This analysis is based on a qualitative study using both indepth interviews and participant observation with Mexican migrant families in the state of New York. This paper primarily draws on interview data, which collected information related to respondents' sociodemographic characteristics and gender, physical activities, dietary habits, health care, quantity and quality of food and drink consumed, and cultural ideas about weight. Interviews focused specifically on respondents' descriptions of the health and physical habits of their children, aged five to twelve, who they raised in the United States. Participant observation consisted of visits to migrants' homes, participation in key moments of food preparation and consumption, and attendance at various recreational and social activities. Field notes recorded special events as well as daily practices of migrant families related to food consumption and physical activities. These observations helped to identify key themes for further exploration in interviews. All of the primary data was collected by the first author and conducted in Spanish. The project was reviewed by the Ethical Review Board of the first author's home university.

In total, the first author completed 35 in-depth interviews, an average of five hours in length, which were completed in one or more meetings with participants. In this paper, we analyze the 30 interviews completed with parents. All of the interviews were tape recorded with the informed consent of participants. Study participants were both male and female migrants living in diverse sociodemographic and economic situations in the state of New York. Participants lived in a variety of different types of communities including large urban centers (New York City, Brooklyn, and Queens), small cities (Saratoga and Albany), and suburban and semirural contexts (Latham, Delmar, Bethlehem, Glenmont, and Slingerlands), as prior research shows geography to shape Mexican migrant women's experiences [17].

Analysis first involved open coding procedures with fully transcribed interview transcripts. Second, we identified patterns in consumption, strategies, and dilemmas around diet despite these geographic differences in residence. Final stages of analysis involved comparing key themes across different groups of migrants, with particular attention to race, class, and gender. All the names reported in what follows are pseudonyms in order to protect the identity of study participants. All the quotes in what follows have been translated from Spanish by the second author.

It is important to note that this study does not use objective measures of weight, height, or BMI to identify the prevalence of overweight or obesity in the sample but rather identifies and analyzes self-reports of weight and perceptions of migrants about overall health and body image. Academic literature has well-established the existence of problems related to overweight and obesity among this population. In what follows we focus on the habits, processes, and perceptions of behavior, particularly as related to childrearing practices that may contribute to these significant health risks.

\section{Results}

3.1. Demographic Profile of Interviewees. The sociodemographic and economic profile of the informants appear in Table 1. Eight of every ten are women; $97.1 \%$ are married or cohabitating and a fourth of the women with legal status migrated for family reunification. Forty-eight percent are undocumented immigrants and half of the children aging 10 and under were born in the US and have dual citizenship. The average age of respondents is 35 years (ranging from 27 to 68 
TABLE 1: Demographic and economic profile of respondents $(n=$ $30)$.

\begin{tabular}{ll}
\hline Characteristics & Percent $(n=30)$ \\
\hline $\begin{array}{l}\text { Level of } \\
\text { education }\end{array}$ & $\begin{array}{l}\text { Elementary }=26.6 \% \\
\text { Middle school or technical degree }=36.8 \% \\
\text { Cigh school }=16.6 \% \\
\text { College graduate or graduate degree }=20.0 \%\end{array}$ \\
\hline Employed $=76.6 \%$ \\
Food service or cleaning $=42.3 \%$ \\
White collar industries $=21 \%$ \\
Occupation & Manual laborers $=13.3 \%$ \\
& $\begin{array}{l}\text { Homemaker }=23.3 \% \text { (all women) } \\
\text { Home-based sales }=16.3 \% \text { (all women) }\end{array}$ \\
\hline $\begin{array}{l}\text { Number of } \\
\text { children }\end{array}$ & Average number of children $=3$ \\
\hline Age of children & $\begin{array}{l}\text { Under age of } 10=42.2 \% \\
\text { Between } 10 \text { and } 20 \text { years old }=31.5 \% \\
\text { Over age of } 20=26.3 \%\end{array}$ \\
\hline Ethnic group & Indigenous Triquis from Oaxaca $=31.0 \%$ \\
\hline $\begin{array}{l}\text { SES status } \\
\text { self-reported) }\end{array}$ & $\begin{array}{l}\text { Lower class }=61.1 \% \\
\text { Middle class }=31.2 \% \\
\text { Upper class }=7.7 \%\end{array}$ \\
\hline
\end{tabular}

years) and the average length of time in the US is 14.2 years (ranging from 8 to 51 years).

Despite differences in class background, education, type of employment, and legal status, participants had the following in common. First, most parents spoke little English, especially women, while most of the children were completely bilingual. Second, all respondents had relied substantially on social networks, depending upon family ties and those of others from their respective communities to find work and housing. Third, most lived with partners. The diaspora represented in the sample is quite large, with migrants coming from 12 states in Mexico: Michoacán, Estado de México, Distrito Federal, Jalisco, Chiapas, Morelos, Yucatán, Tamaulipas, Guanajuato, Tlaxcala, and Puebla y Oaxaca.

3.2. Risk Factors. The academic literature identifies three possible principle risk factors for migrants becoming overweight or obese: premigration conditions related to poverty, lifestyle changes in the host country, and the cultural tendency to view being overweight as a sign of health, well-being, and social status. Our interviews show that, in regard to poverty before migration, migrants who have low income, who are from indigenous backgrounds, and/or who have experienced poverty, food insecurity, and nutritional deficiencies during infancy may, when faced with dietary changes in the United States, be predisposed to becoming overweight or obese after migration. This pattern persists independent of respondents' gender, current class status, and legal status and is especially apparent among the indigenous Triqui population. For example, respondents reported the following:
In my home and my town we always had needs... we were poor and there were many in my family... My parents divided the little bit of food that we had among us all and sometimes they, especially my mom, didn't eat in order to make sure there was food for us. Here in the United States, this doesn't happen. Here there is so much food... I have diabetes. (Pedro, a lower class Triqui who is a father to two children aging 10 and 12)

In my town, when I was a girl, we ate from what we cultivated ourselves, but often times the crops failed... When I first got here I couldn't understand how people can throw out so much food, and I still don't understand... Here there is so much that people don't value it... (Amalia, a lower class mother of three children aging 5, 7, and 11)

Interviews also indicate significant lifestyle changes after migration that may increase the risk of becoming overweight or obese. Informants described an increase in their consumption of fast food and changes in the portions of their meals. They worried about the role of schools in instilling unhealthy dietary habits among their children and the consequences of living in a social environment of abundance combined with the low cost of food products. These concerns were the highest among parents of children aged five to twelve, as they are aware that children develop important dietary habits at this age.

Although interviewees typically indicated consuming fast food and soft drinks only on special days, when asked to recall the times they had eaten outside the home, important patterns emerge according to the age of their children. The groups that are most likely to eat at low-cost chain restaurants like McDonalds are those in which both mothers and fathers work outside home and have young children.

The fact that consumption of fast food is most common among those with small children is interesting given the widespread public campaigns in the United States to reduce obesity and the public discourse that it is best to be thin and watch one's diet. Interviews suggest that the attractiveness of fast food to children, and the pressure to fit in, explains these dynamics.

I don't like it, but... what child does not like to go to McDonalds. (Carmen, a lower class mother of three children aging 5, 7, and 9)

My son loves it. He will tell me: "Mom, let's go out to eat, ok?" Before, during the week, I would go out twice to McDonalds or Burger King or Dunkin Donuts... my son likes the food here more. (Vanesa, a lower class mother of three children aging 4,12 , and 15 )

My middle child is chubby, but he has bad habits and I can't say anything to him about it... He eats hamburgers, French Fries and all of that stuff 
because he spends a lot of time with his friends, and that is what they want to eat. (Alba, upper class mother of three children aging 9,13 , and 16)

Mothers worried about the socialization of their children into the "American diet" and what they eat in school, especially pizza, chicken Nuggets and French fries, hot dogs, and hamburgers.

Well, also one needs to participate in school... If you look at the monthly menu and it is convenient, okay, they can eat it. But when it is pizza two or three days during the week, it is better than they don't. (Amalia, a lower class mother of three children aging 5, 7, and 11)

The problem is the schools... Lunch in the public schools costs 3 dollars and how healthy can the food be that you buy for 3 dollars? (Mauricio, a middle class father of three children aging 5, 7, and 9)

I worked in a school and they give out pizza, hamburgers, spaghetti that tastes bad, because it is cheaper and the school saves... I saw a lot of waste. The [kids] threw out apples or gave them to someone else. (Alba, an upper class mother of three children aging 9,13, and 16)

Despite differences in educational levels and class backgrounds, many had internalized the public discourse about the advantages of "not eating fat, drinking plain water, and making sure meat portions are the size of the palm of your hand." However, the social environment of abundance and the availability of great number and types of food products coupled with the desire to try new foods, their relatively low cost, and different practices around meal portions make it especially likely that families will increase consumption. This, in turn, affects the diet of all family members.

There are things I never had in my house in Mexico and here we do. In Mexico I never had ice cream at home because it costs what, like 60 pesos? It is a luxury item. But here no, it is cheap. So you have ice cream at home and every day you may have ice cream as a dessert, or the box of donuts... and you can eat a donut every day. In Mexico I never bought donuts and here I buy them by the box!! It's the same with Coca Cola that are like 10 cents and even cheaper by the box... Also pre-cooked foods, things that are easy and economical: frozen pizza or frozen French fries... (Sonia, a middle class woman with no children)

Yes, our food habits change. It isn't so much in the sense of your diet, because that is almost the same. At home there is always tortillas and beans. But the difference is in the portions... sometimes all the sweets bother me. Here you have the opportunity to find places to buy sweets in bulk that are cheap... and, well, the kids are happy. (Monica, a lower class mother of three children aging 1,4 , and 6 )

And everywhere there is a school, next door there is a McDonalds or a Seven Eleven, the quickest, and it costs like two dollars for a pizza and a really big soda. And us parents we say, "Well, they have been studying so long, what can I give them?" And it costs two dollars for a pizza and a soda!! (Amalia, a lower class mother of three children aging 5, 7, and 11)

In the cases in which one member of the family is from the United States, parents described the multicultural negotiation of food and consumption habits.

My son eats Mexican food, but more the food from here, the nuggets and hot dogs. I try to give him vegetables like corn and peas, but it is difficult because his mother is totally different with him and is more used to eating the food from here. (Pedro, a lower class Triqui who is a father to two children aging 10 and 12)

I combine with the foods from here, usually on the weekends. We have a barbecue and my daughter is dying for hamburgers and my husband too. So I make myself a steak and them hamburgers. .. yes, we like to eat healthy food, we don't eat junk, like cheap food. And cans, only in an emergency. I never cook from canned foods. (Marta, an upper class mother of a 20 -year-old daughter)

Finally, interviewees also indicate a certain aesthetic or cultural value to being overweight. This appears to be a continuity from the dominant Mexican ideal that "a chubby baby is a beautiful baby."

Well, it depends, if it is excessively fat, then it is healthy. But if it's a bit chubby and full, then yes, [it is cute.] (Monica, a lower class mother of three children aging 1,4 , and 6 )

When you see a child that is all skinny, we think that the mom doesn't take care of her child well, or as we tend to say, "let them eat what they want, because they are small and should gain weight." (Mirna, a lower class mother of three children aging 7,10 , and 12)

3.3. Mother's Strategies. Despite these risk factors, we found a sometimes conflicting awareness of the harm caused by fast food and the consumption of larger portions than in Mexico among families of all socioeconomic and migratory status. Mothers, in particular, utilized the following strategies to avoid bad habits among their children: the highlighting of animal maltreatment, educating children about environmental degradation, and indicating the low quality of the food served by many fast foods restaurants. 
Before it was like once a month that they ate at McDonalds: like a prize if they got an award [at school] or at graduation... Because there are children who go there every day... And I told my son: "I cannot take you there every day" even if it is cheap. Now we go less because it got into their heads that we cannot support that they are cutting down all the trees. (Mirna, a lower class mother of three children aging 7,10, and 12)

With Diego we went once a week to McDonalds. . . but with Jimena, every time we eat at McDonalds she gets diarrhea... Then we got more information about how they treated the cows, how the vegetables were. And I had the children watch a documentary, and they saw the part about the animals and when the part on the vegetables started, "No mommy, don't put this on; we feel really bad." And that is how they became aware of it and now Jimena, actually, calls McDonalds MalDonald's... [Mal is bad in Spanish]. (Nora, a middle class mother of two children aging 8 and 14)

Mothers also used strategies to increase the physical activity of their children and to trick younger children into reducing their consumption of snacks. They also typically avoided taking children with them on weekly shopping trips.

Okay, so today maybe I take them to McDonalds by tomorrow we are going to go to the park... or I'll take them to eat pizza, but all the way up on $82^{\text {nd }}$ street [so they have to walk]. I find ways to get them to move. We sit up there for a while and then we come back, walking the whole way. (Carmen, a lower class mother of three children aging 5, 7, and 9)

You have to trick kids; I buy them chips, but very small bags. Or I buy a big bag and then I give them out just a little at a time. Because if you go to the store, there goes 10 dollars, when with that 10 dollars you could have bought chicken and other things. (Monica, a lower class mother of three children aging 1, 4, and 6)

I don't take the children to the supermarket. My list is mine, because if you take the children they want you to buy a bread, or some cereal... I go at night, when they are sleeping, so I can get only what I need. (Mirna, a lower class mother of three children aging 7, 10, and 12)

3.4. Mothers' Dilemmas. One common practice is to blame the victim for their vulnerable conditions. In this case, it is quite typical to draw on what Saguay [18] calls "blame frames" in explaining the risk factors for becoming overweight or obese. We found that mothers assumed individual responsibility for their children's risk factors rather than viewing them as the result of a larger system that may shape their lifestyle choices. Specifically, women in the study felt guilty about their children's diet and consumption habits. This arises from the gender norm that women are responsible for the well-being of their family members. Interviewees described feelings of guilt around what their children eat, especially for not breastfeeding longer [19] and for relying on fast food given their employment situations.

Because I was working, I couldn't breastfeed, and if I didn't feed her, I didn't have [milk]... I had to use formula even though I knew it wasn't the best thing for my little son. (Jasmin, a lower class mother of a 3-year-old)

Here, and also in Mexico, the campaigns are very strong and they tell you that if we are fat it is your fault. My husband also says that if we are fat it is because of the cook [me]. (Silvia, a middle class mother of three children aging 5, 7, and 9)

If the mother and father are working all the time, who is going to feed the children? With 10 dollars you made a balanced meal [fast food]: a juice, a soda, a fruit and the food. What there isn't is time [to prepare something better]. (Monica, a lower class mother of three children aging 1,4 , and 6 )

Here it is very complicated. When children want a pizza, you give it to them and it is their daily food. Because there is no one to cook... One of my daughter's friends takes for her lunch, every day, bread with peanut butter, every day! (Silvia, a middle class mother of three children aging 5, 7 , and 9)

\section{Discussion}

Existing research shows overweight and obesity to be a significant health and social problem among the Mexican migrant population and outlines the broad quantitative trends and possible consequences of this growing social problem. Few studies, however, identify the processes that may lead to the development of dietary habits and poor nutrition among the Mexican migrant population.

Our findings suggest that migrant families face a number of risk factors for overweight and obesity and that they are well-aware of these risk factors. This is in accordance with Agne et al. [20], who find that perceptions about being overweight or obese among migrants include references to aesthetics, physical symptoms, desires to lose weight, and, particularly relevant to this paper, risks to children's health. It also confirms Lindsay et al. [21] finding in a study of Latino women with preschool aged children that mothers worry that their children will become obese.

Respondents in this study are fully conscious of the current epidemic of overweight and obesity and the importance of maintaining a healthy diet and exercising [16]. This suggests the need to remove the stereotype that migrants, and Mexican migrants in particular, are irresponsible and, as such, are a burden to the social service and health sectors. In 
fact, we found that mothers implement a number of strategies to reduce the consumption of the unhealthy food products that are widely available in the United States.

Mexican migrants in our study, and especially mothers, live with a constant tension between their recognition of the risks of overweight and obesity, the cultural tradition that positively values the chubby bodies of children, and the gendered norms that make mothers responsible for their children's diets. The tension is heightened by their desires to adapt to American society that, in their minds, implies increasing consumption and adopting perceived norms of the host country.

Lindsay et al. [21] have described a similar tension: "Although subjects understood the health and social consequences related to overweight, many discussed the pressures of familial and cultural influences endorsing a 'chubby child"” (p. 113). Because of this, mothers are not able to recognize when their children are overweight and more highly value the general health of their children rather than their weight and size: "In the Latino culture children's weight status reflects parenting skills, and that having a 'skinny' child is a sign of bad parenting and poor health" (p. 113). Although our findings are similar, such a conclusion identifies migrant women as individually responsible for the situation and contributes to "blame frames" surrounding our understanding of risk factors around overweight and obesity among this population.

The cultural practice of associating better health and wellbeing with larger and heavier bodies than considered normal in clinical terms in the United States has been reported by quite a few other authors. Barroso et al. [22], for example, find that children of migrant families attribute this belief to their parents who grew up in poverty and lack of food at home in their countries of origin. Similarly, Candib [4] points out that, among migrants from countries where food can be scarce and malnutrition is common, being overweight tends to be valued as a sign of desirable wealth and health. Cuy Castellanos [13] implies that, among Hispanics in the United States, the consumption of meat and fast food is an indicator of social status because these are practices viewed as a luxury and are associated with higher socioeconomic status.

Our analysis suggests that, over time, migrants tend to modify their perceptions and cultural values from Mexico that being overweight indicates better health, especially of their children. This finding is interesting given that, with time, children born or raised in the United States experience increased risk of obesity and diabetes. This is perhaps due to the acculturation process, which continues regardless of the genetic background and family history of malnutrition and the tendency for the "Hispanic paradox" to decrease with time (the "Hispanic paradox" refers to the finding that recent Latino migrants living in poverty in the United States tend to have better health indicators and lower death rates than the overall population, despite their low socioeconomic status. It is worth noting that various authors estimate that the "Hispanic paradox" disappears among second and third generation migrants as they improve their economic situation and increasingly integrate into US lifestyles [14, 23]).
Our findings confirm those of Greenhalgh and Carney [16] who suggest that there are structural barriers associated with migration that prevent low-income Mexicans in the United States from conforming to American lifestyles and becoming "good citizens," especially in terms of their diet. In their words,

Failure to attain the normative body has led them
to internalize the identity of bad citizens, assume
personal responsibility for their failure, naturalize
the conditions for this failure, and feel that they
deserve this fate. We argue that the blaming of
minorities for the obesity epidemic constitutes
a form of symbolic violence that furthers what
Berlant calls the "slow death" of structurally
vulnerable populations, even as it deepens their
health risks by failing to address the fundamental
sources of their higher weights. ( $p$. 267)

Our qualitative data shows that structural barriers, such as work conditions and availability of low-cost food, exist for migrants of all socioeconomic backgrounds, although they are most acute among the undocumented and the lower class population due to the increased vulnerabilities they face.

\section{Conclusions}

In order to understand the complexity of changing food habits of Mexican migrants in the United States and the possible relationship with problems of overweight and obesity, we must consider gender, class, ethnicity, migratory status, and their intersections. It is also necessary to include a cultural analysis to better understand the ways migrants strategically adopt or resist new dietary lifestyles and consumption habits after migration. Our findings show that among those most at risk of obesity and diabetes among Mexican migrants are the children born and/or raised in the United States due to their genetic predisposition and type of school socialization. Of course, our data relies on reports from parents and not from children; in future research we will consider children's reports about these same risk factors.

Nonetheless, it is this demographic group whose habits we need to understand better and who the government should focus on in order to avoid high heath care costs in the future. It is worth noting that the official discourse tends to blame Latina mothers for this problem and that this position reinforces hegemonic gender norms and does not recognize the economic and social structures that appear to be at the root of Mexican migrant families' consumption habits.

Although we found migrants to be aware of discourses of the benefits of being slim, facing the abundance and availability of low-cost, unhealthy food products makes for an environment that contributes to increases in weight. This structural environment combines with both the cultural values in Mexico that being overweight contributes to better health and a family background of poverty and food insecurity before migration. Taken together the three factors help to explain the prevalence of overweight and obesity among Mexican migrant families and especially children. 
As a result, Mexican migrants suffer from the social costs of the guilt related to being overweight and obese, as it is viewed as an individual responsibility. This is especially true for women who are viewed as being responsible for the families' consumption habits and dietary well-being. As migrants are clearly aware of the obesity epidemic and of their personal risk, our findings support a series of public policy recommendations that may help mothers in their daily practices to resist the consumption of unhealthy food by their children rather than to blame them for their consumption habits.

First, health care programs, particularly related to weight reduction and dietary habits, must recognize the differences in class, gender, ethnicity, age, place of residence, culture, and migratory status. Universal nutritional programs will not address the problems faced by specific populations, such as Mexican migrants. Second, we need to reduce the socalled "acculturation stress" that migrant mothers, above all, experience through programs such as nutritional education clubs, exercise classes, medical orientation, and psychological and legal support services. Third, school foods must be nutritional. Children's access to junk food and cheap foods in and around their schools needs to be eliminated. Fourth, programs should seek to create gender equality around food consumption patterns and take care not to reproduce the hegemonic gender norm that blame women for their children's diet. Although programs may focus on women, men's participation in family consumption decisions should be encouraged.

Finally, above all else, public policy addressing diabetes and the obesity epidemic must operate under the assumption that overweight and obesity are a structural problem and not something that can be overcome solely by the individual.

\section{Conflict of Interests}

The authors declare that there is no conflict of interests regarding the publication of this paper.

\section{Acknowledgments}

The authors would like to thank the Mexican migrants in New York who opened their hearts and shared their concerns and the problems they face on the hard path of creating a dignified life far from their home country. This study was financially supported by the Consejo Nacional de Ciencia y Tecnologia de Mexico (CONACYT) by providing the first author with a sabbatical grant to complete primary data collection. They would also like to thank the University at Albany, SUNY, for the institutional support required to make this study possible.

\section{References}

[1] T. Gill, L. King, and I. Caterson, "Obesity prevention: necessary and possible. A structured approach for effective planning," Proceedings of the Nutrition Society, vol. 64, no. 2, pp. 255-261, 2005.
[2] L. A. Lytle, "Examining the etiology of childhood obesity: the IDEA study," American Journal of Community Psychology, vol. 44 , no. 3, pp. 338-349, 2009.

[3] G. A. Bray, "Obesity: a time bomb to be defused," The Lancet, vol. 352, no. 9123, pp. 160-161, 1998.

[4] L. M. Candib, "Obesity and diabetes in vulnerable populations: reflection on proximal and distal causes," Annals of Family Medicine, vol. 5, no. 6, pp. 547-556, 2007.

[5] I. De Garine and N. J. Pollock, Social Aspects of Obesity, Gordon \& Breach, Amsterdam, The Netherlands, 1995.

[6] M. Delavari, A. L. Sønderlund, B. Swinburn, D. Mellor, and A. Renzaho, "Acculturation and obesity among migrant populations in high income countries-a systematic review," $B M C$ Public Health, vol. 13, no. 1, article 458, 2013.

[7] A. Misra and O. P. Ganda, "Migration and its impact on adiposity and type 2 diabetes," Nutrition, vol. 23, no. 9, pp. 696708, 2007.

[8] C. Boissonnet, H. Schargrodsky, F. Pellegrini et al., "Educational inequalities in obesity, abdominal obesity, and metabolic syndrome in seven Latin American cities: the CARMELA Study," European Journal of Cardiovascular Prevention \& Rehabilitation, vol. 18, no. 4, pp. 550-556, 2011.

[9] G. D. Dinsa, Y. Goryakin, E. Fumagalli, and M. Suhrcke, "Obesity and socioeconomic status in developing countries: a systematic review," Obesity Reviews, vol.13, no. 11, pp. 1067-1079, 2012.

[10] K. R. Flórez, T. Dubowitz, N. Saito, G. Borges, and J. Breslau, "Mexico-United States migration and the prevalence of obesity: a transnational perspective," Archives of Internal Medicine, vol. 172, no. 22, pp. 1760-1762, 2012.

[11] G. Holmboe-Ottesen and M. Wandel, "Changes in dietary habits after migration and consequences for health: a focus on South Asians in Europe," Food \& Nutrition Research, vol. 56, 2012.

[12] Center of Disease Control, National Diabetes Statistics Report, Center of Disease Control, 2014, http://www.cdc.gov/diabetes/ pubs/statsreport14/national-diabetes-report-web.pdf.

[13] D. Cuy Castellanos, "Dietary acculturation in latinos/hispanics in the United States," American Journal of Lifestyle Medicine, vol. 9, no. 1, pp. 31-36, 2015.

[14] K. T. D’Alonzo, S. Johnson, and D. Fanfan, "A biobehavioral approach to understanding obesity and the development of obesogenic illnesses among Latino immigrants in the United States," Biological Research for Nursing, vol. 14, no. 4, pp. 364374, 2012.

[15] US Census Bureau, U.S. Census Bureau Projections Show a Slower Growing, Older, More Diverse Nation a Half Century from Now, US Census Bureau, Suitland, Md, USA, 2012, https://www .census.gov/newsroom/releases/archives/population/cb12-243 .html.

[16] S. Greenhalgh and M. Carney, "Bad biocitizens?: latinos and the US 'obesity epidemic'” Human Organization, vol. 73, no. 3, pp. 267-276, 2014.

[17] J. Dreby and L. Schmalzbauer, "The relational contexts of migration: Mexican women in new destination sites," Sociological Forum, vol. 28, no. 1, pp. 1-26, 2013.

[18] A. Saguay, What's Wrong with Fat, Oxford University Press, Oxford, UK, 2012.

[19] D. Cartagena, S. W. Ameringer, J. M. McGrath, S. W. Masho, N. Jallo, and B. J. Myers, "Factors contributing to infant overfeeding in low-income immigrant Latina mothers," Applied Nursing Research, vol. 28, no. 4, pp. 316-321, 2015. 
[20] A. A. Agne, R. Daubert, M. L. Munoz, I. Scarinci, and A. L. Cherrington, "The cultural context of obesity: exploring perceptions of obesity and weight loss among Latina immigrants," Journal of Immigrant and Minority Health, vol. 14, no. 6, pp. 1063-1070, 2012.

[21] A. C. Lindsay, K. M. Sussner, M. L. Greaney, and K. E. Peterson, "Latina mothers' beliefs and practices related to weight status, feeding, and the development of child overweight," Public Health Nursing, vol. 28, no. 2, pp. 107-118, 2011.

[22] C. S. Barroso, R. J. Peters, R. J. Johnson, S. H. Kelder, and T. Jefferson, "Beliefs and perceived norms concerning body image among African-American and latino teenagers," Journal of Health Psychology, vol. 15, no. 6, pp. 858-870, 2010.

[23] J. M. McWilliams, A. M. Zaslavsky, E. Meara, and J. Z. Ayanian, "Health insurance coverage and mortality among the nearelderly," Health Affairs, vol. 23, no. 4, pp. 223-233, 2004. 


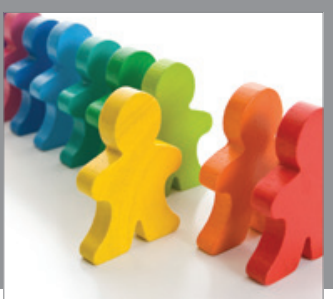

Autism

Research and Treatment
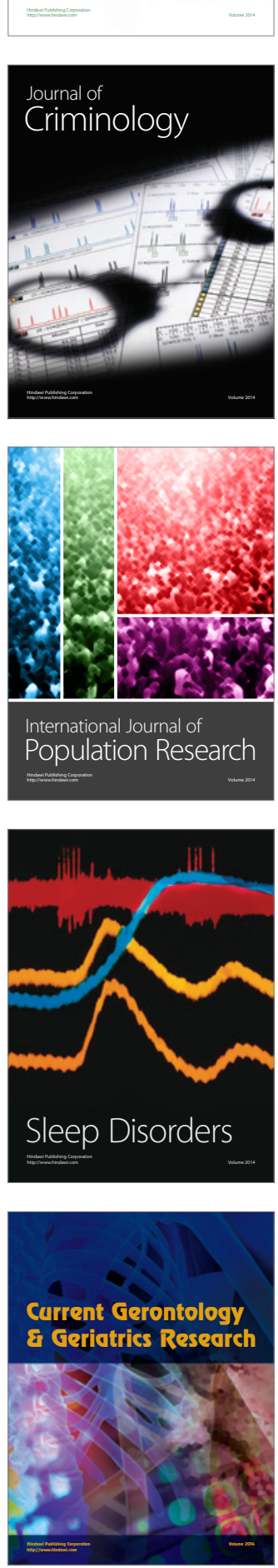

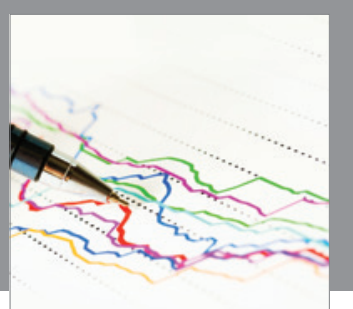

Economics

Research International
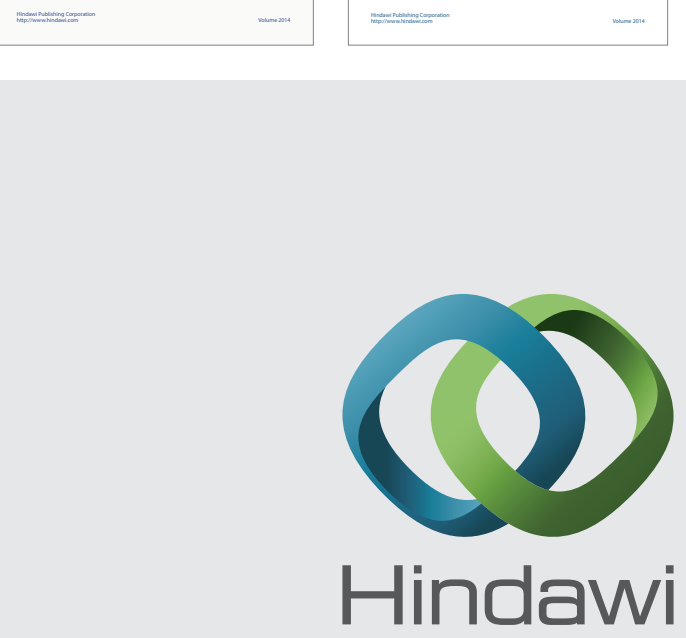

Submit your manuscripts at

http://www.hindawi.com
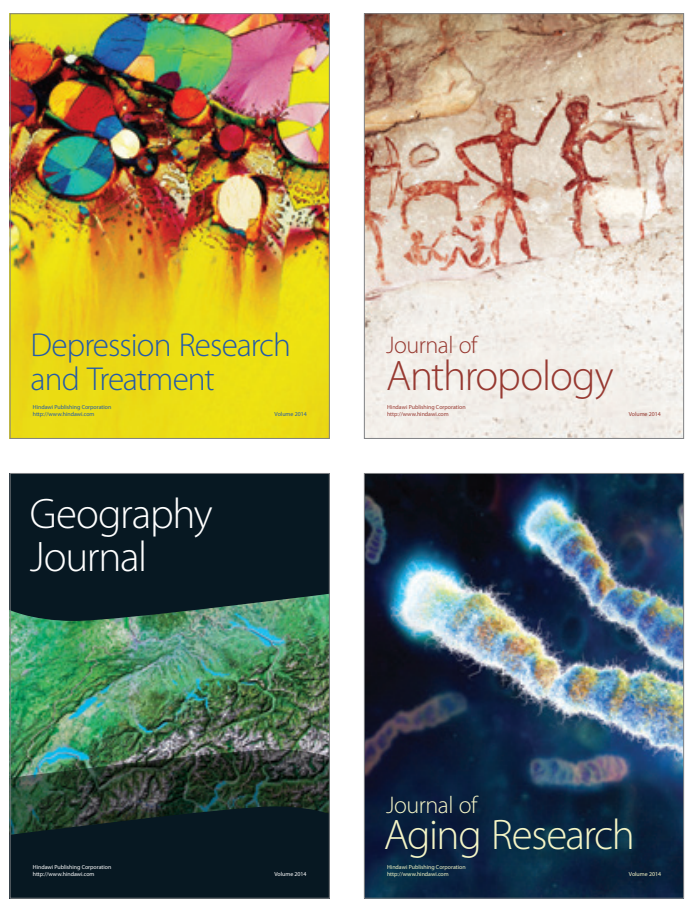
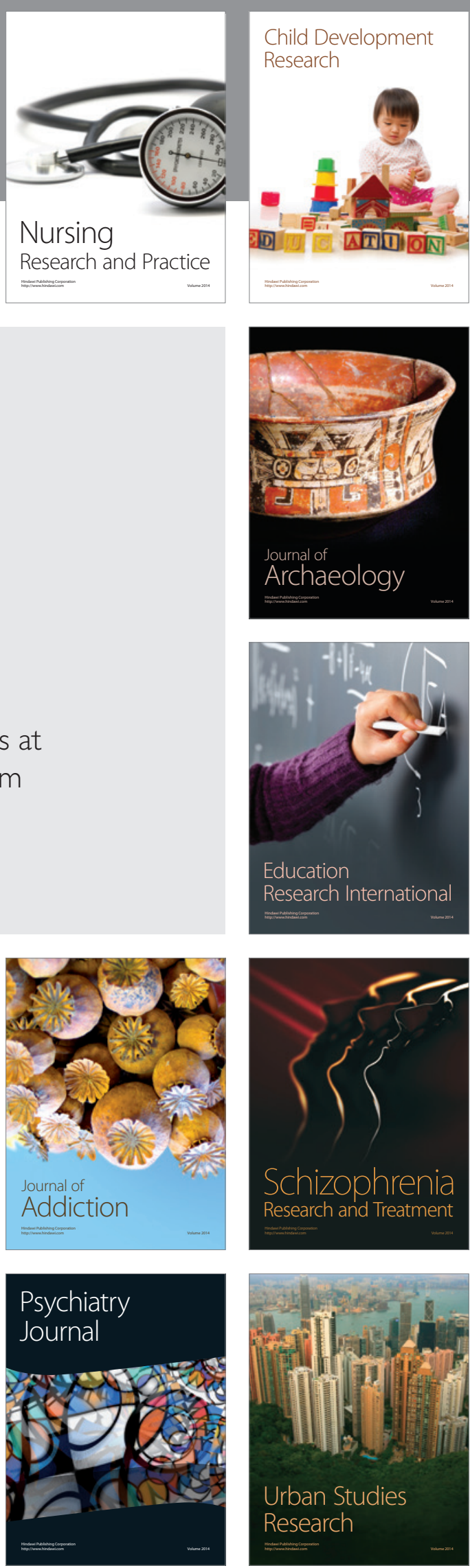